\title{
A META-ANALYSIS ON THE EFFECTIVENESS OF MALARIA COMMUNITY-BASED INTERVENTION
}

\author{
Norain Ahmad ${ }^{1}$, Nurul Afzan Aminuddin ${ }^{1}$, Sharifah Fazlinda Syed Nor ${ }^{1}$, Mohd Nazrin \\ Jamhari ${ }^{1}$, Ahmad Farid Nazmi Abdul Halim ${ }^{1}$, Hasanain Faizal Ghazi ${ }^{2}$, Mohammed Saffree \\ Jeffree $^{3}$, Syed Sharizman Syed Abdul Rahim ${ }^{3}$, Norfazilah Ahmad ${ }^{1}$, Azmawati Mohammed \\ Nawi ${ }^{1}$, Mohd Rohaizat Hassan ${ }^{1 *}$ \\ ${ }^{1}$ Department of Community Health, Faculty of Medicine, Universiti Kebangsaan Malaysia, Kuala \\ Lumpur, Malaysia. \\ ${ }^{2}$ College of Nursing, Al-Bayan University, Baghdad, Iraq \\ ${ }^{3}$ Faculty of Medicine \& Health Sciences, University Malaysia Sabah.
}

*Corresponding author: rohaizat@ppukm.ukm.edu.my

\begin{abstract}
Introduction: The community-based intervention was proven as one of the best approaches in combatting malaria. It is widely used to reduce malaria cases worldwide. A multisectoral approach must be made to ensure the success of the intervention. Therefore, this study is aimed is to determine the effectiveness of community-based intervention for malaria based on recent findings. Methods: A search strategy using Pub Med and Cochrane database platform investigating the effectiveness of malaria community-based intervention. There are selected terms and words predefined to obtain a comprehensive search strategy that included text fields within records and Medical Subject Headings (MeSH terms). Results: Eight articles were selected for this study. This review identified six communitybased interventions for malaria and four outcome measures. Most of the studies included a low risk of bias in each criterion except for random sequence and allocation of concealment. The meta-analysis found that the overall incidence difference of the included studies was significant $(0.05 \mathrm{Cl} 0.02,0.08)$, while the subgroup analysis of Permethrin LLIN the 12 was reduced to $75 \%$. However, the overall usage percentage difference in health education and community mobilization to improve intervention usage was not significant $(0.28 \mathrm{Cl}-0.02,0.58)$. Conclusion: The community-based intervention approach is practical to fight malaria thus, to reduced mortality due to malaria. An integrated approach and engagement with multiagency will ensure outstanding achievement in fighting malaria.
\end{abstract}

Keywords: Community-based, malaria, intervention, Meta-analysis 


\section{Introduction}

Malaria is a vector borne disease caused Plasmodium sp. parasites that transmitted to human bitten by the vector, infected female Anopheles sp. Mosquitoes. Even though it is a life-threatening disease, it is preventable and curable. Way back to malaria history globally, the malaria eradication programs that were launched in 1955 by the 8th World Health Assembly. Since most of countries in the Americas and Europe, and in the majority of countries of Asia and Oceania initiated the program and very later after that was African region (World Health Organization, 2002).

Gratefully to know that the world data report in 2017 showed decreasing number of malarial cases from 2010 to 2017 however the difference not significant in the year 2015 to 2017. Most malaria cases were reported from WHO African Region (92\%), followed by the WHO South-East Asia Region (5\%) and the WHO Eastern Mediterranean Region (2\%)(World Health Organisation, 2018). It also reported that Plasmodium falciparum is the most prevalent malaria parasite in the WHO African Region, WHO regions of South-East Asia, the Eastern Mediterranean and the Western Pacific. Whereby in WHO Region of Americas is predominant by $\mathrm{P}$. vivax representing the malaria cases.

Malaria infection is fatal if not treated accordingly. In 2017, there were an estimated 435000 deaths from malaria globally and the African region accounted for the majority of the death (93\%), and children under five years are the most vulnerable to death (World Health Organisation, 2018). Besides that, a pregnant woman is 3 times more likely to suffer severe disease after a malaria infection compared to non-pregnant women (Tillotson \& Tillotson, 2009). Nevertheless, the baby also prone to stillbirth, low birth weight and congenital malaria (De Beaudrap et al.,2013; Omer et al., 2017; Schant-Dunn, \& Nour, 2009). In other aspects, malaria burden the economics of the country. A study in Zambia showed It was found the cost per rapid diagnostic tests (RDTs) administered was estimated to be USD4.39, while the cost per artemether- lumefantrine (AL) treatment administered was estimated to be USD34.74 (Silumbe et al., 2015). It is much costly compared to the annual per capita cost of malaria control programme which only USD2.21 (Shretta, Avanceña \& Hatefi, 2016).

Therefore, the World Health Organization (WHO) with their tremendous efforts fighting malaria by series of programmes, guidelines, surveillances and intervention (World Health Organization, 2019). One of the best approaches in controlling and preventing malaria infection is by introducing the communitybased intervention. The types of community-based intervention that had been done are; i)insecticidetreated nets (ITNs), ii)indoor residual spraying (IRS), iii) impregnated bed sheets, iv)intermittent preventive therapy (IPT), v)health education and vi)environmental management (Owusu-Addo E., 2014; Salam et al., 2014). The study determines that most community-based interventions will give positive result in ITNs ownership and usage, parasitaemia, anaemia and other adverse health outcomes such as stunting, wasting, and stillbirth (Salam et al., 2014). Intervention combating malarial must be done in collaboration by multisectoral and agencies. It will include the elimination of breeding places, mobilizing supportive community participation, team building of healthcare staff, public health 
department staff, general practitioners, youth club members and the co-operative societies. (Shinde et al., 2015) .

At our level of knowledge, the latest systematic review on community-based intervention for malaria was published in 2014 based on the articles of the 1990s to the early year of 2000s (Salam et al., 2014). Therefore, the objective of this present study is to determine the effectiveness of community-based intervention for malaria based on recent findings.

\section{Methods}

\section{Literature search}

A systematic literature search of Pub Med and Cochrane database platform was conducted in March 2019. There are selected terms and words that were predefined to obtain a comprehensive search strategy and that included text fields within records and Medical Subject Headings (MeSH terms). The keywords used are malaria OR mesh word(malaria) OR plasmodium AND "community-based intervention". The searching flow diagram is shown in Figure 1.

A total of 36 studies published from January 2000 until December 2018 were found using the key words mentioned. Nine article was rejected because of duplication. Only 11 articles selected after title screening in which were further filtered based on the inclusion and exclusion criteria. The inclusion criteria included were randomised controlled trials / experimental / quasi experimental studies on malaria interventions. Observational studies, protocol, review papers, no full-text, non-English language articles and published before year 2000 were excluded from further analysis, which gave the total of 8 selected articles for full text review and further analysis. Each article was reviewed by at least two reviewers using GRADE risk of bias checklist and if there was any disagreement between the 2 reviewers, third reviewer opinion will be sought and agreed upon.

This study aimed to determine the effectiveness of community intervention of Malaria. During the article search, the keyword use is not included in the outcome element to widen the exploration of the effectiveness element been studied. Although there are several outcomes found including usage of LLIN, Malaria incidence, knowledge toward malaria disease, care-seeking behaviour and compliance with $\mathrm{IMCl}$, only two (2) outcomes were included in the meta-analysis which are Malaria incidence and usage of LLIN. 


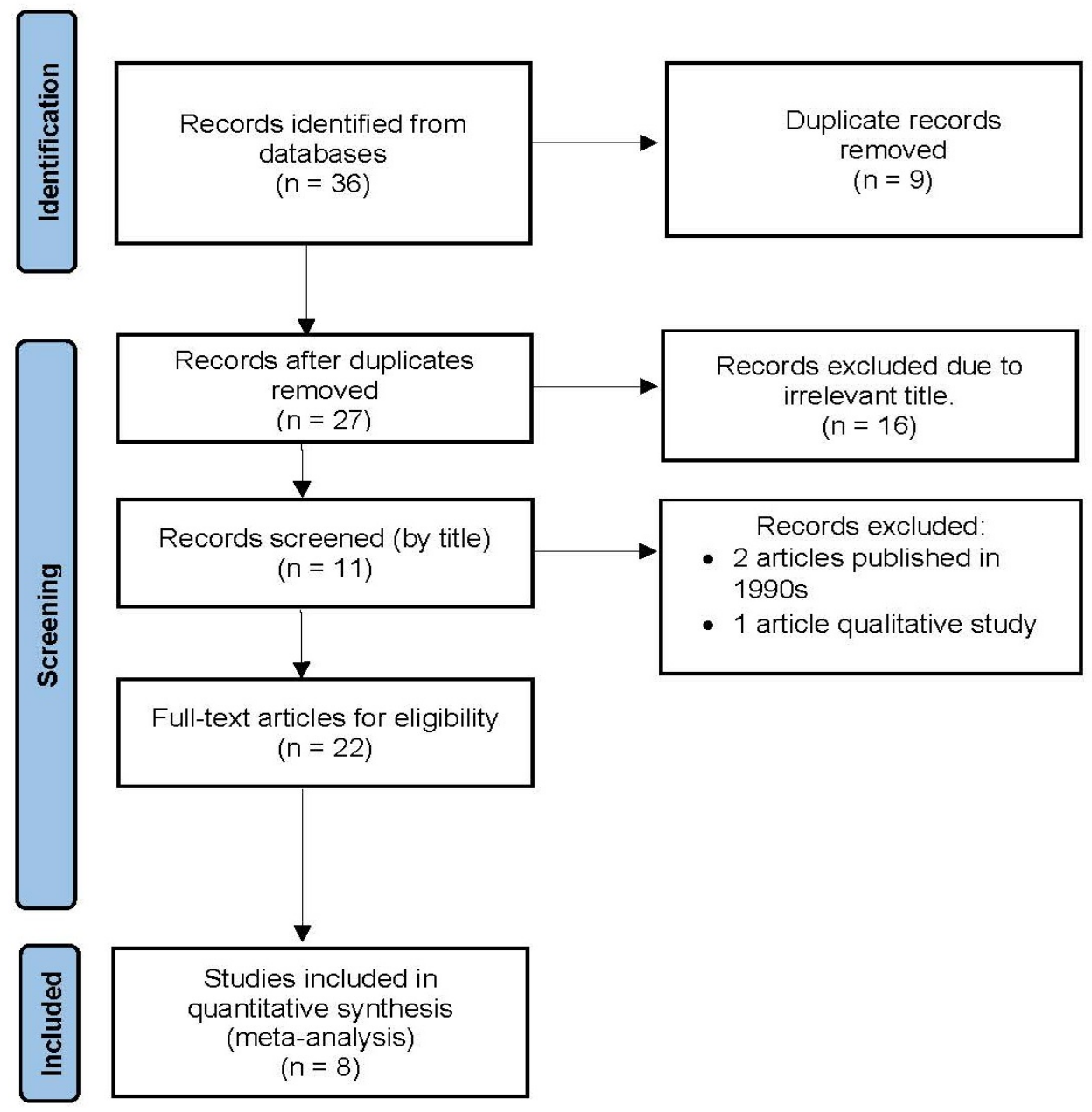

Figure 1: Flow process

\section{Data extraction}

The characteristics of the studies were extracted in a table. The information extracted include a) author and year of publication, b) country of study, c) the study design, d) sample population, e) intervention \& duration, f) outcomes of the study, g) intervention group and h) control group.

\section{Critical appraisal}

The studies were assessed based on six criteria; sequence allocation, allocation concealment, blinding, incomplete outcome data, selective reporting, and other sources of bias and will be decided as 'low risk' when there was no evidence of risk in the article, 'high risk' when there was obvious bias identified in the article and 'unclear' when there was insufficient evidence for conclusion of a bias.

\section{Data analysis}

The effect size of this study was measured by calculating the prevalence difference of vaccination coverage and timeliness of vaccine intake between the intervention and the control group using $95 \%$ Confidence Interval $(C l)$. The overall effect (pooled prevalence difference) was determined by $Z$ test 
with $p<0.05$ was considered as significant. The heterogeneity was determined by $X^{2}$ and $l^{2}$ test, whereby $p<0.1$ and $l^{2}>50 \%$ considered as heterogeneous. Random effect model was used when there was evidence of heterogeneity as opposed to fixed effect model when there was evidence of homogeneity. Publication bias was assessed by using funnel plot. Analyses were done using Review Manager 5.3.

\section{Results}

\section{Characteristics of reviewed articles}

A total of 8 articles that eligible to be included in this review whereby 6 studies are from India and 1 from each Africa and Vietnam as showed in Table 1. The community-based intervention for malaria identified are: 1) Supportive supervision \& community mobilization (1 study), 2) LLIN - permethrin (2 studies) -deltamethrin (1 study), 3) LLIH (Hammock) - permethrin (1 study), 4) Permethrin plastic sheet (1 study), 5) Health trainer (1 study), 6) Household education and training (1 study). Besides that, the outcomes measured are: 1) Utilization or usage of LLIN (2 studies), 2) Care seeking behaviour (1 study), 3) Compliance to $\mathrm{IMCl}$ (1 study), 4) Knowledge towards malaria disease (2 studies), 5) Malaria incidence rate ( 1 study), Malaria cumulative incidence ( 3 studies).

\section{Risk of Bias}

In the risk of bias assessment, most included studies contained a low risk of bias in each criterion except for random sequence and allocation of concealment. Figure 2 showed four studies that did not meet the random sequence generation criteria whilst three studies did not meet the allocation of concealment risk criteria. One thing worth noted that almost all the studies did mention whether blinding of participants and personnel was carried out. 
Table 1: Characteristics of the included studies

\begin{tabular}{|c|c|c|c|c|c|c|c|}
\hline $\begin{array}{l}\text { Author, } \\
\text { Year }\end{array}$ & Country & $\begin{array}{l}\text { Study } \\
\text { design }\end{array}$ & $\begin{array}{c}\text { Sample } \\
\text { population }\end{array}$ & $\begin{array}{c}\text { Intervention } \\
\& \\
\text { Duration }\end{array}$ & Outcome & $\begin{array}{l}\text { Intervention } \\
\text { Group }\end{array}$ & $\begin{array}{l}\text { Control } \\
\text { Group }\end{array}$ \\
\hline $\begin{array}{l}\text { (Das et } \\
\text { al., 2014) }\end{array}$ & $\begin{array}{l}\text { Odisha, } \\
\text { India. }\end{array}$ & $\mathrm{RCT}$ & Household & $\begin{array}{l}\text { Supportive } \\
\text { supervision } \\
\& \\
\text { Community } \\
\text { mobilization } \\
12 \text { months }\end{array}$ & $\begin{array}{l}\text { Consistent } \\
\text { usage of } \\
\text { LLINs } \\
\text { Care } \\
\text { seeking } \\
\text { behaviour }\end{array}$ & $\begin{array}{l}3571 / 4224 \\
261 / 378\end{array}$ & $\begin{array}{l}3219 / 4093 \\
248 / 365\end{array}$ \\
\hline $\begin{array}{l}\text { (Winch et } \\
\text { al., 2003) }\end{array}$ & Africa & Cluster RCT & $\begin{array}{l}\text { Carer of } \\
\text { children in } \\
10 \text { health }\end{array}$ & $\begin{array}{l}\text { Health } \\
\text { trainer } \\
3 \text { months }\end{array}$ & $\begin{array}{l}\text { Compliance } \\
\text { with IMCl } \\
\text { regime } \\
\text { Knowledge } \\
\text { of malaria } \\
\text { danger } \\
\text { signs }\end{array}$ & $\begin{array}{l}109 / 152 \\
100 / 145\end{array}$ & $\begin{array}{l}29 / 134 \\
44 / 143\end{array}$ \\
\hline $\begin{array}{l}\text { Duc et al., } \\
\text { 2009) }\end{array}$ & Vietnam & Cluster RCT & $\begin{array}{l}30 \text { Villages } \\
\text { (Population } \\
18646)\end{array}$ & $\begin{array}{l}\text { Permethrin } \\
\text { Long } \\
\text { Lasting } \\
\text { Insecticidal } \\
\text { Hammocks } \\
\text { (LLIH)24 } \\
\text { months }\end{array}$ & $\begin{array}{l}\text { Malaria } \\
\text { Incidence } \\
\text { rate }\end{array}$ & $\begin{array}{l}92 / 9453.5 \\
\text { new cases } \\
\text { per person } \\
\text { sem }\end{array}$ & $\begin{array}{l}132 / 10706 \\
\text { new cases } \\
\text { per } \\
\text { person } \\
\text { sem }\end{array}$ \\
\hline $\begin{array}{l}\text { (Sharma } \\
\text { et al., } \\
\text { 2009b) }\end{array}$ & India & Cluster RCT & 3 village & $\begin{array}{l}\text { Permethrin } \\
\text { plastic sheet } \\
\text { (ZeroFly) } \\
8 \text { months }\end{array}$ & $\begin{array}{l}\text { Malaria } \\
\text { Cumulative } \\
\text { Incidence }\end{array}$ & $13 / 330$ & $51 / 382$ \\
\hline $\begin{array}{l}\text { (Sharma } \\
\text { et al., } \\
2009 a)\end{array}$ & India & Cluster RCT & 22 Village & $\begin{array}{l}\text { Permethrin } \\
\text { LLIN } \\
12 \text { months }\end{array}$ & $\begin{array}{l}\text { Malaria } \\
\text { Cumulative } \\
\text { Incidence }\end{array}$ & $\begin{array}{l}16 / 211 \\
\text { LLIN }\end{array}$ & $\begin{array}{l}48 / 265 \\
\text { Untreated } \\
\text { neat }\end{array}$ \\
\hline \multirow[t]{2}{*}{$\begin{array}{l}\text { Chourasia } \\
\text { et al., } \\
2014 \text { ) }\end{array}$} & \multirow[t]{2}{*}{ INDIA } & \multirow[t]{2}{*}{$\begin{array}{l}\text { Quasi- } \\
\text { Experimental }\end{array}$} & \multirow[t]{2}{*}{$\begin{array}{l}218 \\
\text { households } \\
\text { in two } \\
\text { villages }\end{array}$} & \multirow[t]{2}{*}{$\begin{array}{l}\text { Household } \\
\text { training vs. } \\
\text { mass } \\
\text { campaigns } \\
4 \text { months }\end{array}$} & Knowledge & \multicolumn{2}{|c|}{$\begin{array}{l}\text { Mean difference between } \\
\text { the two groups was } 0.547 \\
(95 \% \mathrm{Cl}: 0.18-0.91)(\mathrm{P}- \\
\text { value of } 0.004)\end{array}$} \\
\hline & & & & & $\begin{array}{l}\text { Proportion } \\
\text { utilizing } \\
\text { LLIN }\end{array}$ & $57 / 108$ & $27 / 110$ \\
\hline $\begin{array}{l}\text { (Dev et } \\
\text { al., 2010) }\end{array}$ & $\begin{array}{l}\text { Assam } \\
\text { India }\end{array}$ & $\begin{array}{l}\text { Quasi- } \\
\text { Experimental }\end{array}$ & Village & $\begin{array}{l}\text { Permethrin } \\
\text { LLIN } \\
10 \text { months }\end{array}$ & $\begin{array}{l}\text { Malaria } \\
\text { Cumulative } \\
\text { Incidence }\end{array}$ & $36 / 2603$ & $190 / 2950$ \\
\hline $\begin{array}{l}\text { (Dev et } \\
\text { al., 2011) }\end{array}$ & India & $\begin{array}{l}\text { Quasi- } \\
\text { Experimental }\end{array}$ & Village & $\begin{array}{l}\text { Deltamethrin } \\
\text { LLIN } \\
9 \text { months }\end{array}$ & $\begin{array}{l}\text { Malaria } \\
\text { cumulative } \\
\text { incident } \\
\text { Mosquito } \\
\text { mortality }\end{array}$ & $\begin{array}{l}31 / 2100 \\
80 / 80\end{array}$ & $\begin{array}{l}69 / 2068 \\
7 / 80\end{array}$ \\
\hline
\end{tabular}



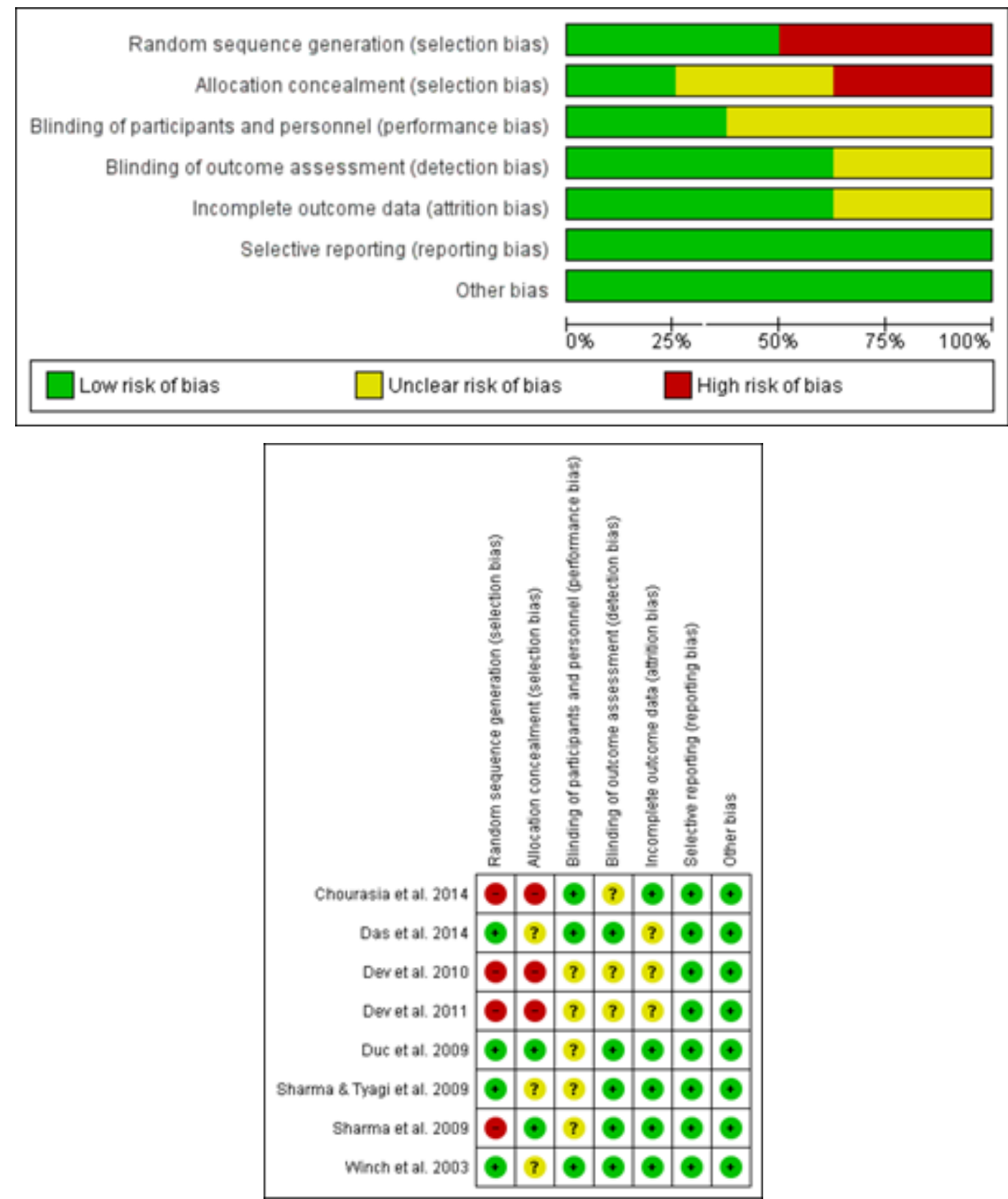

Figure 2: Risk of bias result

\section{Meta-analysis}

In the meta-analysis, the overall incidence difference of the included studies was significant $(0.05 \mathrm{Cl}$ $0.02,0.08$ ) although there was high heterogeneity which was at $98 \%$ (Figure 3). However, in the subgroup analysis of Permethrin LLIN, the $\mathrm{I}^{2}$ was reduced to $75 \%$ and the result was also significant $(0.07 \mathrm{Cl} 0.02,0.12)$. 


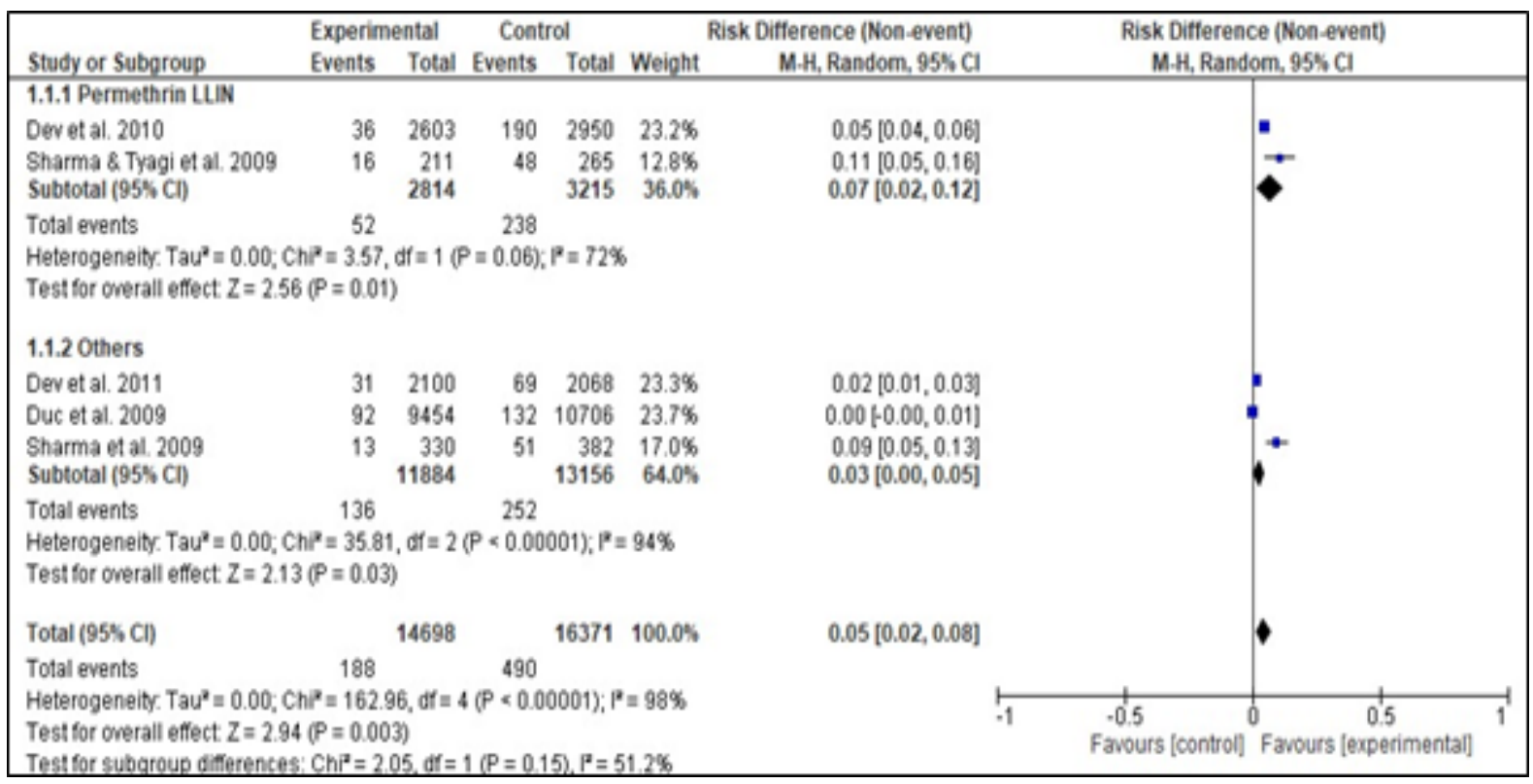

Figure 3: Effectiveness of community-based intervention in terms of malaria incidence

In terms of the effectiveness of health education and community mobilization to improve intervention usage, the overall usage percentage difference was not significant $(0.28 \mathrm{Cl}-0.02,0.58)$ as pictured in Figure 4.

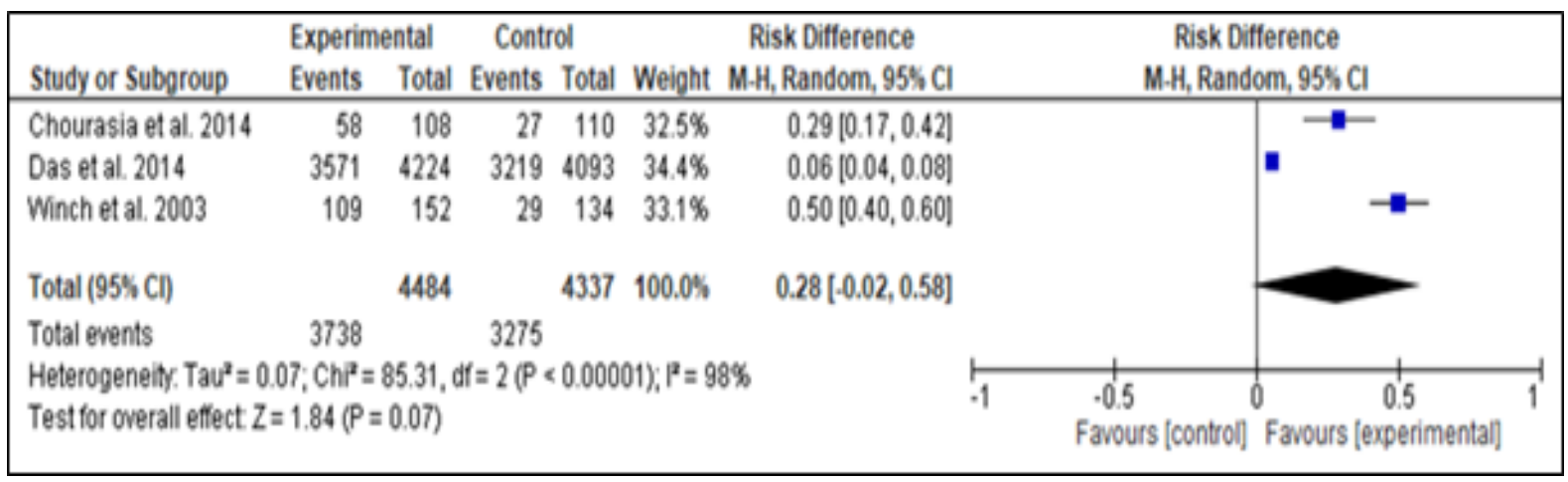

Figure 4. Effectiveness of health education and community mobilization to improve intervention usage

The funnel plot for the studies included in the incidence analysis was visually symmetrical, meaning that there was unlikely any publication bias detected (Figure 5). 


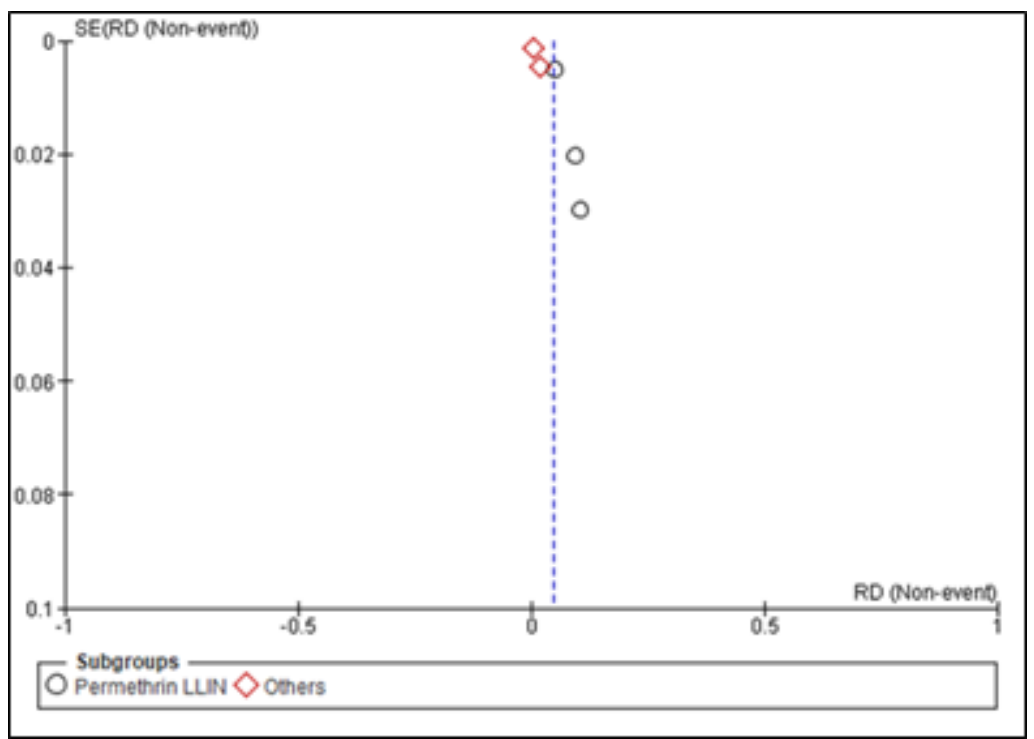

Figure 5 Funnel plot

\section{DISCUSSION}

The meta-analysis result shows there is a significant difference in Malaria incidence between intervention and control group. However, the results having high heterogeneity figure (98\%). This may be due to the difference of population been studied, mainly from India and others country include Africa and Vietnam. The variety of population may result in a different geographical area, environment, social, and behavioural which may impact the study outcome. For example, Duc et al studied the population live in the forest and like to sleep outside by using hammocks (Duc et al., 2009). Other studied populations are using LLIN inside their home ((Dev et al., 2010, Dev et al., 2011) and Sharma et al studied the mobile population and used permethrin zero Fly plastic sheet instead of LLIN (Sharma et al., 2009a).

The outcome measured differently across the studies such as Duc et al used lab-test (rapid test P.falciparum specific, P.vivax and Pan-Malaria) and microscopic blood smear examination and measured incidence rate instead of cumulative incidence (Duc et al., 2009). Whereas other studies used only used Malaria microscopic blood smear only to confirm the diagnosis (Sharma et al., 2009a, Sharma et al., 2009b). The study method to detect the Malaria cases after intervention also differs, in example some study used passive surveillance (Dev et al., 2010, Duc et al., 2009) and other study performing active case detection (Dev et al., 2011, Sharma et al., 2009a, Sharma et al., 2009b). The community intervention approach also varies, such as LLIN (2 types; deltamethrin and permethrin), LLIH (long lasting insecticide hammocks), Permethrin plastic sheet (ZeroFly), health education with different approaches including household training, mass campaigns, health trainer, supportive supervision \& community mobilization which have different degree of strength toward outcome measured in the study. 
The other outcome that was analysed in this meta-analysis was the usage of intervention. It was noted health education and community mobilization do not affect on the usage of intervention. However, there are only three studies included in this analysis. It was also noted that there was high heterogeneity that could be due to different interventions applied in the three studies included. Winch et al. (2003) implemented health education on Integrated Child Management IIIness specifically for malaria whilst the intervention in Das et al.(2014) was about community mobilization on good health behaviour. On the other hand, Chourasia et al. (2014) intervention was about household training on the effective usage of LLINs. Although all three studies included were about intervening health behaviour through health education and community mobilization, the implementation process differs so as the sample population involved. (Winch et al., 2003) specifically targeted carers of children whereas Chourasia et al.(2014) targeted the tribal population in the endemic regions which were quite similar to Das et al. (2014). However, Das et al. (2014) used a much larger sample size which gave weight to the result of the analysis.

This study included the latest articles published since the year 2000 compared to a previous review article that included article less than years 2000 (Salam et al., 2014). We used the Cochrane search engine which is known to have high-quality paper and PubMed increase the search coverage. Our study limitation is, we only used 2 search engines which may limit the coverage of article search. Most of the studies are mainly from India and less from Southeast Asia and specifically from Malaysia. By looking at the funnel plot, there is no evidence of publication bias however there is lacked smaller-scale studies evident by the missing gap in the base of the funnel. This could be explained by smaller studies were very rarely published in high impact journal making them not being picked up by the two search engines that were used.

\section{CONCLUSION}

The community-based interventions showed effectiveness in reducing the incidence of malaria to achieve a successful malaria elimination program. It is recommended for integrating interventions and approach in maintaining effectiveness of the community-based intervention for malaria elimination program.

\section{ACKNOWLEDGMENTS}

We would like to thank the Dean, Faculty of Medicine, University Kebangsaan Malaysia for his permission to publish this systematic review.

\section{Conflicts of Interest}

The author declares no conflicts of interest. 


\section{References}

- Chourasia, M. K., Abraham, V. J. \& John, J. 2014. Household training vs. mass campaigns: a better method of health communication for preventing malaria. Trop Doct, 44(4): 196-200. https://doi: 10.1177/0049475514545201

- Das, A., Friedman, J., Kandpal, E., Ramana, G. N., Gupta, R. K. D., Pradhan, M. M. \& Govindaraj, R. 2014. Strengthening malaria service delivery through supportive supervision and community mobilization in an endemic Indian setting: an evaluation of nested delivery models. Malaria Journal, 13:482. https://doi.org/10.1186/1475-2875-13-482

- De Beaudrap, P., Turyakira, E., White, L. J., Nabasumba, C., Tumwebaze, B., Muehlenbachs, A., Guérin, P. J., Baum, Y., McGready,R. 2013. Impact of malaria during pregnancy on pregnancy outcomes in a Ugandan prospective cohort with intensive malaria screening and prompt treatment. Malaria Journal, 12(1): 1-11. https://doi:10.1186/1475-2875-12-139

- Dev, V., Phookan, S., Padhan, K., Tewari, G. G. \& Khound, K. 2011. Laboratory wash-resistance and field evaluation of deltamethrin incorporated long-lasting polyethylene netting (Netprotect $₫$ ) against malaria transmission in Assam, North-east India. Acta Trop, 119(2-3): , 172-7. https://doi: 10.1016/j.actatropica.2011.05.013.

- Dev, V., Raghavendra, K., Barman, K., Phookan, S. \& Dash, A. P. 2010. Wash-resistance and field efficacy of Olyset net, a permethrin-incorporated long-lasting insecticidal netting, against Anopheles minimus-transmitted malaria in Assam, Northeastern India. Vector Borne Zoonotic Dis, 10(4): 403-10. https://doi: 10.1089/vbz.2008.0191

- $\quad$ Duc, T. N., Erhart, A., Speybroeck, N., Xuan, X. N., Ngoc, T. N., Van, K. P., Le Xuan, H., Le Khanh, T., Coosemans, M. \& D'alessandro, U. 2009. Long-lasting insecticidal hammocks for controlling forest malaria: a community-based trial in a rural area of Central Vietnam. PLOS One, 4(10):e7369. https://doi: 10.1371/journal.pone.0007369

- $\quad$ Omer, S. A., Idress, H. E., Adam, I., Abdelrahim, M., Noureldein, A. N., Abdelrazig, A. M., Elhassan, M. O., Sulaiman, S.M. 2017. Placental malaria and its effect on pregnancy outcomes in Sudanese women from Blue Nile State. Malaria Journal, 16(1):1-8. https://doi:10.1186/s12936-017-2028-0

- $\quad$ Owusu-Addo E., S. B. O. 2014. Effectiveness of Health Education in Community-based Malaria Prevention and Control Interventions in sub Saharan Africa: A Systematic Review. Journal of Biology, Agriculture and Healthcare, 4(3): 22-34

- Salam, R. A., Das, J. K., Lassi, Z. S. \& Bhutta, Z. A. 2014. Impact of community-based interventions for the prevention and control of malaria on intervention coverage and health outcomes for the prevention and control of malaria. Infectious Diseases of Poverty, 3(1): 1-15. https://doi:10.1186/2049-9957-3-25

- $\quad$ Schant-Dunn, J. \& Nour, N. M. 2009. Women's health in the developnig world. Malaria and Pregnancy, 2(3): 186-192. https://doi:10.3909/riog0091

- $\quad$ Sharma, S. K., Tyagi, P. K., Upadhyay, A. K., Haque, M. A., Mohanty, S. S., Raghavendra, K. \& Dash, A. P. 2009a. Efficacy of permethrin treated long-lasting insecticidal nets on malaria transmission and observations on the perceived side effects, collateral benefits and human safety in a hyperendemic tribal area of Orissa, India. Acta tropica, 112(2): 181-187.

- $\quad$ Sharma, S. K., Upadhyay, A. K., Haque, M. A., Tyagi, P. K., Mohanty, S. S., Mittal, P. K. \& Dash, A. P. 2009b. Field evaluation of ZeroFly ${ }^{\circledR}-A n$ insecticide incorporated plastic sheeting against malaria vectors \& its impact on malaria transmission in tribal area of northern Orissa. Indian Journal of Medical Research, 130(4): 458-466.

- $\quad$ Shinde, R., Rasal, M., Waghmare, R., Meshram, P. \& Khobragade, P. 2015. A community based model for effective malaria control in a known endemic area of a metropolitan city. International Journal of Community Medicine and Public Health, 2(2): 101. https://doi:10.5455/23946040.ijcmph20150506

- Shretta, R., Avanceña, A. L. V. \& Hatefi, A. 2016. The economics of malaria control and elimination: a systematic review. Malaria Journal, 15(1):1-14. https://doi:10.1186/s12936-0161635-5

- $\quad$ Silumbe, K., Yukich, J. O., Hamainza, B., Bennett, A., Earle, D., Kamuliwo, M., Steketee, R. W., Eisele,T.P., Miller,J.M. 2015. Costs and cost-effectiveness of a large-scale mass testing and treatment intervention for malaria in Southern Province, Zambia. Malaria Journal, 14(1): 1-13. https://doi:10.1186/s12936-015-0722-3

- $\quad$ Tillotson, G. S. \& Tillotson, J. 2009. Infectious Diseases in Obstetrics and Gynecology. Expert Review of Anti-infective Therapy, 7(4): 413-414. https://doi:10.1586/eri.09.9 
- Winch, P. J., Bagayoko, A., Diawara, A., Kane, M., Thiero, F., Gilroy, K., Daou, Z., Berthe, Z. \& Swedberg, E. 2003. Increases in correct administration of chloroquine in the home and referral of sick children to health facilities through a community-based intervention in Bougouni District, Mali. Transactions of the Royal Society of Tropical Medicine and Hygiene, 97(5): 481-490.

- World Health Organization. 2002. Community involvement in rolling back malaria. http://www.paho.org/hq/index.php?gid=18295\&option=com_docman\&task=doc_view

- World Health Organization. 2018. World Malaria Report 2018. World Health Organization. http://www.who.int/iris/handle/10665/275867

- World Health Organization. 2019. Compendium of who malaria guidance. https://apps.who.int/iris/handle/10665/312082. 